\title{
Autonomy supportive and controlling leadership as antecedents of work design and employee well-being
}

Business Research Quarterly

(C) The Author(s) 2021

Article reuse guidelines:

sagepub.com/journals-permissions DOI: 10.1 I 77/234094442। 1054508 journals.sagepub.com/home/brq

\author{
Pallavi Sarmah' (iD, Anja Van den Broeck ${ }^{1,2}$, \\ Bert Schreurs ${ }^{3}$, Karin Proost ${ }^{1,4}$ and Filip Germeys ${ }^{\prime}$
}

\begin{abstract}
The continuation of work that undermines employee well-being necessitates an investigation into the antecedents of work design. Therefore, we examined how autonomy supportive and controlling leadership-as defined in self-determination theory (SDT) - relate to employees' job resources, job demands, and well-being. Using a cross-sectional $(N=50 \mathrm{I})$ and a daily diary study $(N=123)$, we found that autonomy supportive leadership relates to employees' work engagement via job resources both at the between- and within-person levels. However, only the cross-sectional study evidenced a relationship between autonomy supportive leadership and exhaustion via job resources. Controlling leadership related to exhaustion via job demands at the between-person level in both studies but not at the within-person level. Alongside implications for the literature on SDT, work design theory, the leadership literature, and workplace re-enchantment, we advance concomitant insights to practitioners.
\end{abstract}

JEL CLASSIFICATION: I3I, J8I, MI2

\section{Keywords}

Autonomy supportive leadership, controlling leadership, job demand resources model, self-determination theory, employee well-being

It is only through enforced standardization of methods, enforced adoption of the best implements and working conditions, and enforced cooperation that this faster work can be assured. And the duty of enforcing the adoption of standards and enforcing this cooperation rests with management alone.

—Frederick Winslow Taylor

It doesn't make sense to hire smart people and tell them what to do; we hire smart people so they can tell us what to do.

-Steve Jobs

The quotes of Taylor and Jobs capture a century of evolving perspectives on what constitutes high-quality work, and how leadership should be oriented to make such work accessible to employees. The ideas surrounding work design - that is, "the content and organization of one's work tasks, activities, and relationships" (Parker, 2014, p. 662) - have undergone major shifts over the past century (Parker, Morgeson, \& Johns, 2017). During the prime of Taylor's (1911) scientific management, ideally designed work was thought to include simplified and repetitive tasks that promote worker specialization and increase organizational productivity. As a consequence, leaders were expected to assert control over the organizational clockwork and instrumentalize employees (Al-Amoudi, 2019) by assigning simplified and monotonous tasks, conveying strict instructions, and enforcing a system of incentives and penalties (Taylor, 1911).

\footnotetext{
'Department of Work and Organisation Studies, KU Leuven - Campus Brussels, Belgium

${ }^{2}$ Optentia, North-West University, Vanderbijlpark, South Africa

${ }^{3}$ Vrije Universiteit Brussels, Brussels, Belgium

${ }^{4}$ Open University of the Netherlands, Heerlen, The Netherlands

Corresponding author:

Pallavi Sarmah, Department of Work and Organisation Studies, KU

Leuven - Campus Brussels, Warmoesberg 26, 1000 Brussels, Belgium.

Email: pallavi.sarmah@kuleuven.be
} 
However, over time such systems led employees to be demotivated, stressed, counterproductive, and resentful toward their leaders (Oldham \& Fried, 2016). This prompted scholars to reconsider the Tayloristic approach and undertake a paradigm shift that focused on converting dehumanizing workplaces into enchanting, human-centric work stations (Boje \& Baskin, 2011). Today, concerns for employee motivation and well-being have become an indispensable part of the conversation surrounding work design. In addition, ideas about leadership are also being modified to be compatible with work designs which include more job resources, that is, motivation fostering aspects of work such as autonomy and learning opportunities, and fewer job demands, that is, health-impairing aspects of work such as role problems (Demerouti et al., 2001).

However, most research examining the influence of work design and leadership on employee well-being have been conducted in isolation from one another, thereby preventing theoretical integration of naturally integrated workplace processes. Such lack of integration is highlighted by work design scholars, who have voiced the need for future research examining leadership as antecedents of work design (Parker, Van den Broeck, \& Holman, 2017). In addition, leadership scholars have also called for integrative research that links specific theory-driven choice of leadership behaviors to positive and negative forms of employee well-being (e.g., work engagement and exhaustion) via congruent mediators (Inceoglu et al., 2018).

Given that employee motivation serves as a common underlying denominator which links leadership, work design, and employee well-being, we attempt to address the aforementioned appeals for integrative research by using self-determination theory (SDT; Deci \& Ryan, 2000; Gagné \& Deci, 2005) - a motivation theory-to investigate leadership as an antecedent of employees' work design and well-being. SDT specifies that both social (e.g., leaders) and structural (e.g., work design) factors in the work setting can foster employees' autonomous and controlled motivation, and consequently their well-being. We aim to address how different leadership styles (as described in SDT) may relate to different aspects of employees' work design - as modeled in the Job Demands Resources (JDR) Model - and thereby also to their well-being.

According to SDT (Gagné \& Deci, 2005), leaders may differ in the degree to which they foster autonomous motivation (such that employees engage in their work because they find it meaningful or enjoyable) or controlled motivation (such that employees engage in their work because they feel an internal or external pressure to do so). Autonomy supportive leaders seek to foster autonomous motivation among employees, for example, by offering choices and making work a valuable experience. Controlling leaders in contrast actively foster controlled motivation among employees, for example, through deploying contingent rewards, threatening with sanctions, and/or using pressure tactics based on guilt and shame induction. Recent meta-analytic findings confirm that when leaders are perceived as autonomy-supportive, their employees report higher autonomous and lower controlled motivation and therefore experience more well-being and work engagement (Slemp et al., 2018). In addition, research on controlling leadership shows that the more employees consider their leader as controlling, the less likely they are to report good psychological health and work satisfaction (Moreau \& Mageau, 2012).

While findings such as those of Slemp et al. (2018) and Moreau and Mageau (2012) provide valuable insights on the links between motivating approaches of leaders and employee well-being, they do not illustrate whether such relationships could be fostered through structural aspects of work such as job demands and job resources. Lack of such knowledge not only stunts theoretical advances but also limits practitioners from having clear guidelines on how leaders may maximize on the benefits of work designs to ensure continued support toward employees' wellbeing. Therefore, in this article, we expand on the extant literature and investigate how work design as a mediator may channel the influences of autonomy supportive and controlling leadership toward employee well-being.

In the current study, thus, we first theoretically integrate the fields of leadership and work design by adopting an SDT-based motivational lens to distinguish leadership styles. Second, by investigating how such leadership styles influence work design, we highlight the motivational conduit linking leader behavior to work design and contribute to both work design theory and SDT. Moreover, we also examine how such links between leadership and work design affect employee well-being. In doing so, we contribute to the leadership literature, which has thus far paid little attention to how leadership may be linked to positive and negative aspects of employee well-being such as work engagement and exhaustion (Inceoglu et al., 2018).

Finally, we also advance the leadership literature and SDT by including the darker side of leadership and examining its effects on work design and employee well-being. While some studies have tapped into the associations between leadership and work design (e.g., Fernet et al., 2015; Rahmadani et al., 2020), the focus of those studies have been mostly limited to rather positive forms of leadership such as transformational and engaging leadership. Since scholars have expressed much concern over the prevalence of negative forms of leadership (Aasland et al., 2010; Schyns \& Schilling, 2013), it is equally pertinent to explore how leadership styles that presumably have less beneficial consequences for employees, such as controlling leadership, influence the work design process.

We thus expand our knowledge about controlling leadership, which is a seemingly adverse, motivation-based, social interaction style whose influence although rigorously studied within other life domains such as parenting 
(Mageau et al., 2015) and education (Aelterman et al., 2019) has been largely neglected in the work context (Slemp et al., 2018, but see Moreau \& Mageau, 2012, for an exception). By comparing the effects of autonomy supportive and controlling leadership as two contrasting leadership styles, this study provides valuable insights to practitioners about how to shape leadership trainings such that managers can foster work designs that promote favorable forms of employee motivation and well-being. We also inform them that leadership - through its association with work design - could be instrumental to the process of workplace re-enchantment, that is, the process of converting dehumanized workspaces which undermine human agency into empowering places that engender work meaningfulness among resourceful and engaged employees (Boje \& Baskin, 2011).

\section{Work design and employee well- being}

The relationship between work design and employee wellbeing has been rigorously studied and documented for more than a century now (Parker, Morgeson, \& Johns, 2017). However, it continues to pique the interest of researchers as ever-changing organizational structures and systems require continuous re-evaluation of how to support employee well-being through high-quality work (Grant \& Parker, 2009; Pfeffer, 1995). One of the theoretical advances that has been instrumental in explaining and predicting employee well-being over a range of working conditions is the JDR model (Bakker \& Demerouti, 2017; Demerouti et al., 2001). Within this model, job demands refer to "physical, psychological, social, or organizational aspects of the job that require sustained physical and/or psychological (cognitive and emotional) effort or skills and are therefore associated with certain physiological and/or psychological costs" (Bakker \& Demerouti, 2007, p. 312). Job resources, however, encompass "physical, psychological, social, or organizational aspects of the job that ... (1) [are] functional in achieving work goals, (2) reduce job demands and the associated physiological and psychological costs, [or] (3) stimulate personal growth, learning, and development" (Bakker \& Demerouti, 2007, p. 312).

Job demands require employees to exert effort at work, which may consequently tax their physical and mental energy, and lead them to experience physical strains, psychological overexertion, and fatigue (Bakker \& Demerouti, 2007; Demerouti et al., 2001). Because of their energydepleting effects, job demands elicit a health-impairing process which leads to exhaustion (Bakker \& Demerouti, 2007). Job resources, in contrast, are highly motivating. Their presence facilitates employees to achieve their work goals, enhance personal growth, and satisfy basic needs (Bakker \& Demerouti, 2007). Job resources thus cater both extrinsic and intrinsic motivation of employees. As such, job resources are expected to contribute to enhanced wellbeing and high levels of work engagement among employees (Bakker \& Demerouti, 2007).

Research applying the JDR model shows that job demands (e.g., emotional demands and role conflict) are responsible for a wide range of negative health outcomes among employees such as emotional exhaustion and burnout, whereas job resources (e.g., autonomy and learning opportunities) are crucial for enhancing employees' work engagement (Nahrgang et al., 2011). Furthermore, albeit not stipulated in the original JDR model (Demerouti et al., 2001), Schaufeli and Bakker (2004) also predicted and found that job resources relate negatively to exhaustion. Based on the conservation of resources theory (Hobfoll, 1989), they argue that a lack of job resources may make employees more vulnerable to feeling depleted. As such, having adequate job resources may create twin advantages: on one hand, it may foster work engagement and, on the other hand, it may prevent exhaustion (Schaufeli, 2017). A recent meta-analysis of longitudinal studies by Lesener et al. (2019) confirms this assertion and shows that while work engagement is only fostered by job resources, exhaustion can be elicited by job demands and prevented by job resources. Given that job demands and job resources play a vital role in influencing employee well-being, it becomes pertinent to study how they are created in the workplace.

\section{Leadership, job demands, and job resources}

Research shows that leaders may influence employees' perceptions about job demands and job resources, which can consequently influence their well-being. Fernet et al. (2015), for example, found transformational leadership to negatively associate with cognitive, emotional, and physical job demands and positively with job resources. Other studies show that having an engaging leader is related to more job resources, fewer job demands, higher work engagement, and lower burnout (Rahmadani et al., 2020; Schaufeli, 2015).

Engaging leadership is an SDT-inspired, recently developed leadership construct that elaborates on leadership orientations aimed at fostering employees' motivation and engagement by empowering, strengthening, and connecting employees (Schaufeli, 2015). Although it has been linked to leader-facilitated satisfaction of basic psychological needs (i.e., autonomy, competence, and relatedness), engaging leadership is yet to be thoroughly embedded within the broader SDT literature (Schaufeli, 2015; Van Tuin et al., 2020).

Therefore, upon careful consideration, the extant literature seems to remain inadequate in two fronts. First, they link multi-facet leadership styles such as transformational 
leadership - which was originally conceptualized with performance and organizational effectiveness in mind - to other outcomes such as employee well-being and work design (Inceoglu et al., 2018). Hence, such researches are often criticized for incoherent theorizing, as they fail to explain the mechanisms by which such relationships materialize (Inceoglu et al., 2018). Second, since research in this context has largely examined positive forms of leadership, there is a dearth of information about what happens at the other, equally important, "dark" side of leadership.

In response, we aim to build on and extend the aforementioned line of research by adopting a single motivational framework, well-grounded within SDT, to investigate the effects of leadership on employees' perceived work design and subsequent well-being. In addition, by comparing the effects of both autonomy supportive and controlling leadership, we adopt a well-balanced approach to examine leadership as an antecedent of work design (Parker, Van den Broeck, \& Holman, 2017).

\section{Autonomy supportive leadership: an antecedent of job resources and employee well-being}

Autonomy supportive leadership refers to a style of leadership where the focus is on leading employees by promoting their autonomous motivation (Slemp et al., 2018). Autonomous motivation is defined as engaging in an activity out of self-determined motivation, for example, because one considers it enjoyable or interesting (i.e., intrinsic motivation), or, valuable or infused with personal meaning (i.e., identified regulation) (Deci \& Ryan, 2000). Leaders who seek to foster autonomous motivation take interest in their employees' perspectives, offer them opportunities for choice and initiative, and provide them with meaningful rationales for doing their task when choice is not possible (Deci \& Ryan, 1987). Autonomy supportive leaders believe in respecting their employees' opinions and are committed to nurturing their personal interests by using inviting and respectful communication styles (Haerens et al., 2018).

Such efforts of the leader may influence employees' work designs - both objectively as well as perceptually and, thereby, also influence employees' well-being in terms of work engagement and exhaustion (Schaufeli \& Bakker, 2004). Extant literature shows that to motivate their employees, autonomy supportive leaders indeed allow them to exercise autonomy, pursue their interests, and build their skills to enhance competence (Slemp et al., 2018). When leaders allow their employees to initiate and fulfill self-conceived projects, they consequently also help their employees to identify with their tasks and thrive at work (Jiang et al., 2020). Moreover, autonomy supportive leaders also ensure that when they make an inflexible request to their employees, the rationale behind the request is adequately conveyed so that employees can see the significance and value of that work (Slemp et al., 2018). Therefore, by infusing motivating job characteristics into their employees' work designs, autonomy supportive leaders actively contribute to their employees' job resources.

Apart from making objective changes to the work design of their employees, autonomy supportive leaders may also change employees' perceptions about their work designs. According to the social information processing approach (SIPA; Salancik \& Pfeffer, 1978), the social context of a workplace directs employees' attention toward certain information, making the information so salient that it predominantly shapes their ideas about how the context looks like, and which behaviors are expected of them. In other words, social contexts assist employees' sense-making process and provides them with a guide to normative beliefs, attitudes, and reasons for actions (Salancik \& Pfeffer, 1978). In the context of autonomy supportive leadership, by providing choice, supporting initiatives, and accommodating employees' perspectives, autonomy supportive leaders are likely to create a social context which clearly communicates resource availability and the leader's support toward employees using those resources (Baard et al., 2004; Slemp et al., 2018). Hence, by creating an affable social context, autonomy supportive leaders enhance resource salience in their employees' perception (Salancik \& Pfeffer, 1978) and encourage them to use those resources (Gagné \& Deci, 2005; Slemp et al., 2018).

To summarize, we advance that autonomy supportive leaders may not only contribute to their employees' objective job resources, but may also accentuate the perceptual salience of those resources by creating a congruous social context. Since enhanced job resources contribute to employees' well-being by fostering their work engagement, and reducing their susceptibility to exhaustion (Lesener et al., 2019; Schaufeli, 2017), we hypothesize,

Hypothesis 1. Job resources mediate the positive relationship between autonomy supportive leadership and work engagement, and the negative relationship between autonomy supportive leadership and exhaustion.

\section{Controlling leadership: an antecedent of job demands and employee well- being}

In line with SDT, controlling leadership style can be defined as a social influence process through which leaders foster controlled work motivation among employees (Moreau \& Mageau, 2012). Controlled motivation is typified by feelings of being pressured by others or oneself to engage in particular activities (Deci \& Ryan, 2000). Employees who are motivated in a controlled way may experience pressure to follow others' biddings so that they may achieve rewards 
(e.g., bonus, promotion) and/or avoid punishments (e.g., being fired; that is, external regulation) (Deci \& Ryan, 2000). Controlled motivation may also include employees feeling pressurized by self-created regulations that make their self-worth dependent upon their work, which consequently prompts them to work to either feel good about themselves or to avoid feeling bad (e.g., guilty or ashamed; that is, introjected regulation) (Deci \& Ryan, 2000). Controlling leaders elicit such type of motivation by restricting the locus of control to themselves, thus limiting their employees' self-determination and pressurizing them into following their lead (Moreau \& Mageau, 2012).

Controlling leaders issue inflexible and rigid orders and gain the compliance of their followers by using contingent rewards/punishments (e.g., putting at stake a desirable outcome, say their holiday bonus) or by threatening with penalizations (e.g., pay-cuts) if employees show deviance (Hodge \& Lonsdale, 2011; Reeve et al., 2014). They may also rely on guilt and shame induction, and/or the use of harsh language to bypass their employees' opinions, needs, interests, and emotions, thereby executing their personal standards by triggering feelings of contingent self-worth (Haerens et al., 2018).

It is noteworthy that, although other negative forms of leadership such as petty tyranny (Ashforth, 1994) and destructive leadership (Schyns \& Schilling, 2013) may also encompass similar leader behavior, such leadership styles differ from controlling leadership because they specify intentions that are unrelated to fostering self-determination among employees, and unlike the notion of controlling leadership, do not specify the intended outcome of leader behavior. For instance, while a leader's sustained display of follower-directed hostile behavior can be categorized as either abusive supervision or destructive leadership (Schyns \& Schilling, 2013), such acts would qualify as controlling leader behavior only if they were used as a tactic to demotivate employees from violating orders.

Through the use of techniques that foster controlled motivation, controlling leaders may influence employees' objective and perceived job characteristics, and consequently influence their well-being. When controlling leaders levy strict impositions and try to control their employees instead of helping them find inherent pleasure and value through work, their employees feel pressurized (Moreau \& Mageau, 2012) and may endure various job demands. By adopting an authoritarian approach, using harsh language for communication, and being non-inclusive of employees' preferences (Reeve, 2009), controlling leaders may create emotionally demanding situations for employees (Haerens et al., 2018).

Moreover, controlling leaders do not explain to their employees why they expect them to behave in a particular way, and instead, they either demand complete obedience of orders or use guilt induction when employee behave differently (Reeve, 2009). This could prompt employees into simply fulfilling the leaders' orders, which could potentially lead to workplace conflicts. For instance, when there is an incongruence between what a controlling leader expects employees to do and what the employees themselves perceive as being the purpose of their job, or what others (e.g., co-leaders, colleagues, or customers) require (Haerens et al., 2018), it could lead to role conflicts. In sum, by maintaining monopoly over work proceedings and intruding upon the thoughts and feelings of the workers through harsh language, controlling leaders may actively contribute to their employees' job demands, which in turn could foster exhaustion.

Apart from actually increasing the number and level of job demands, at a perceptual level too, controlling leadership may have rather detrimental implications for employees' work designs and well-being. The incessant communication of orders by controlling leaders, declarations about strict deadlines, and threats against non-compliers strongly enhance the salience of job demands that employees are expected to fulfill at the workplace (Salancik \& Pfeffer, 1978). Therefore, to summarize, we advance that controlling leaders may not only increase their employees' job demands, but may also accentuate the perceptual salience of those demands by creating a congruous social context. Given that the JDR model states that job demands deteriorate employees' well-being and promote exhaustion, we hypothesize,

Hypothesis 2. Job demands mediate the positive relationship between controlling leadership and exhaustion.

Figure 1 depicts our research model, which we tested through a cross-sectional survey study (Study 1) and a complementary daily diary study (Study 2 ). We used the crosssectional data of Study 1 as the starting point of our analyses to efficiently use our resources and check whether our research questions deserve further attention (Spector, 2019). However, cross-sectional data may suffer from problems such as retrospective bias and may not solely suffice for establishing reproducibility of results (Shafer \& Dexter, 2012). Hence, to put more faith in our results, we retested our model in Study 2, now using a stronger research design (i.e., a repeated-measures or daily diary design), which allowed us to rule out problems associated with the use of "one-shot" cross-sectional designs, such as retrospective biases (Ohly et al., 2010). Moreover, given that diary study designs allow hypothesis testing at both the between and within-person level (Ohly et al., 2010), Study 2 also helped us to check for the reproducibility of our results.

\section{Study I}

\section{Method}

Participants and procedure. In Study 1, we made use of data that were collected as part of a larger survey on employee 


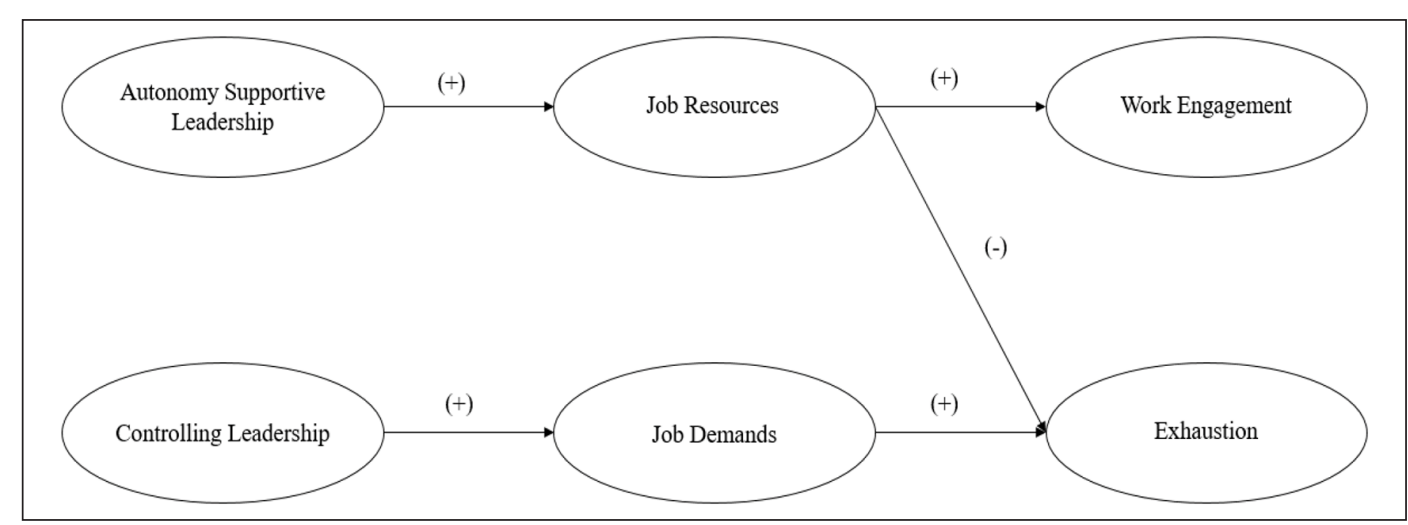

Figure I. Hypothesized theoretical model highlighting effects of autonomy supportive and controlling leadership on work engagement and exhaustion as mediated by job resources and job demands.

well-being in 2007. In total, 1,050 questionnaires were distributed electronically or via paper-pencil surveys across seven different organizations in Belgium. These included three organizations active in industry, three government organizations, and one service organization. Participation was voluntary and anonymous. Informed consent was obtained from all participants. In total, 672 respondents returned the survey (response rate $=64 \%$ ). The dataset was then prepared for analysis by list-wise deletion of entries containing straightlining/non-differentiation and missing values to prevent systematic measurement errors (Loosveldt \& Beullens, 2017). The resulting dataset contained 501 entries of which $45 \%$ were male and $55 \%$ were female. The average age of participating employees was 40.91 years $(S D=10.34)$, while their average organizational tenure was 11.54 years $(S D=10.38)$. The sample consisted of $76 \%$ full-time employees and $24 \%$ part-time employees, and majority of our sample had permanent employment contracts $(92 \%)$.

\section{Measures}

Autonomy supportive and controlling leadership. Autonomy supportive leadership was measured with the six items of the short Work Climate Questionnaire by Baard et al. (2004). The items tapped into, for example, the degree to which employees perceived their leader as accommodative of their perspectives (e.g., "understands how I see things," "listens to how I want to approach things in my work," "asks my opinion about my work, before suggesting how things should be done") and providing choices and meaningful explanations for doing particular tasks (e.g., "offers me options," "confirms my confidence to bring my work to a successful conclusion," "encourages me to ask questions"). Four items were used to assess controlling leadership style. Drawing from the well-cited scale of parental psychological control of Barber (1996), we used two items which seemed most suitable for the context of work and tapped into the degree to which leaders exert control by directly rewarding and punishing particular employee behaviors (e.g., "often reveals my previous mistakes when he/she evaluates my work") or by controlling how they feel (e.g., "less friendly to me when I don't see things the way he/she sees them"). We also used two self-developed items (i.e., "wants to have control over my tasks" and "is demanding and strict") for assessing the overall degree to which employees perceived their leader as controlling. Employees indicated how often their leaders displayed autonomy supportive and controlling behaviors on a scale from 1 ("never") to 5 ("always"). ${ }^{1}$

Job Demands were measured using the commonly experienced demands of emotional demands and role conflict on a 5-point Likert-type scale ranging from 1 ("totally disagree") to 5 ("totally agree"). Three items of emotional demands (e.g., "My work is emotionally demanding.") were chosen from the scale developed by Notelaers et al. (2007). Role conflict was measured using five items (e.g., "I get conflicting assignments from my immediate superior.") from Biessen and De Gilder (1993).

Job Resources were measured using the constructs autonomy and learning opportunities, which are common across occupations. A 5-point Likert-type scale ranging from 1 ("totally disagree") to 5 ("totally agree") was used to measure both job resources. In line with Baillien et al. (2011), autonomy was measured using five items (e.g., "I can plan my own work") from Rosenthal et al. (1996). Learning opportunities were measured using four items (e.g., "At work I have the opportunity to further improve my skills") from Veldhoven and Meijman (1994).

Work engagement and exhaustion. Work engagement was measured using the 3-item Ultra-Short Measure for Work Engagement of Schaufeli et al. (2019), which included items like "At my work, I feel bursting with energy." We measured exhaustion using five items (e.g., "I feel emotionally drained from my work") from Schaufeli and Van Dierendonck (2000). Respondents indicated their answers on both measures using a 7-point Likert-type scale ranging from 1 ("never") to 7 ("always, everyday"). 
Table I. Means, standard deviations, Cronbach's alphas, and correlations among the study variables of Study I.

\begin{tabular}{|c|c|c|c|c|c|c|c|c|c|c|}
\hline & $M$ & $S D$ & 1 & 2 & 3 & 4 & 5 & 6 & 7 & 8 \\
\hline I. ASL & 3.27 & 0.90 & $(.92)$ & & & & & & & \\
\hline 2. $\mathrm{CL}$ & 1.98 & 0.73 & $-.34 * * *$ & $(.69)$ & & & & & & \\
\hline 3. Emotional Demands & 2.45 & 0.95 & -.01 & $.27 * * *$ & $(.85)$ & & & & & \\
\hline 4. Role Conflict & 2.19 & 0.66 & $-.27 * * *$ & $.36 * * *$ & $.23 * * *$ & $(.86)$ & & & & \\
\hline 5. Autonomy & 3.11 & 0.80 & $.26 * * *$ & -.08 & -.02 & -.06 & $(.78)$ & & & \\
\hline 6. Learning Opportunities & 3.75 & 0.69 & $.48 * * *$ & $-.12 * *$ & .01 & $-.22 * * *$ & $.37 * * *$ & $(.85)$ & & \\
\hline 7. Work Engagement & 4.72 & 0.99 & $.3 I^{* * *}$ & $-.13 * *$ & -.02 & $-.26 * * *$ & $.09 *$ & $.44 * * *$ & $(.8 \mathrm{I})$ & \\
\hline 8. Exhaustion & 1.51 & 1.15 & $-.21 * * *$ & $.17 * * *$ & $.13 * *$ & $.30 * * *$ & $-.10 *$ & $-.19 * * *$ & $-.19 * * *$ & $(.92)$ \\
\hline
\end{tabular}

SD: standard deviation; ASL: autonomy supportive leadership; CL: controlling leadership.

$\mathrm{N}=50 \mathrm{I}$. Cronbach's alphas are reported on the diagonal.

$*_{p}<.05$.

$* * p<.01$.

$* * * p<.001$

Analysis. To test our hypotheses, we conducted structural equation modeling as proposed by Anderson and Gerbing (1988) in Mplus software version 8 (Muthén \& Muthén, 2017). First, a confirmatory factor analysis (CFA) was done to assess the goodness of fit of our measurement model. A good model fit is obtained when comparative fit index (CFI) and Tucker-Lewis index (TLI) values are larger than or equal to 0.9 , and root mean square error of approximation (RMSEA) and standardized root mean square residuals (SRMR) values are lower than or equal to 0.06 and 0.08, respectively (Hu \& Bentler, 1999). Second, we tested our mediation hypotheses by estimating the structural model using standardized coefficients obtained through maximum likelihood estimation. In line with Preacher et al.'s (2010) recommendations, we used a parametric bootstrap procedure and computed $95 \%$ confidence intervals around all effect estimates to account for the asymmetric sampling distribution of the (indirect) effects.

\section{Results}

Descriptive statistics and model fit. The means, standard deviations, internal consistencies, and correlations among the study variables are shown in Table 1. A measurement model was estimated to confirm the distinctiveness of our constructs, using the scale means of learning opportunities and job autonomy as indicators of job resources, and the scale means of role conflict and emotional demands as indicators of job demands. The other variables (i.e., autonomy supportive leadership, controlling leadership, work engagement, and exhaustion) were measured with their respective items. The measurement model was found to have a good fit with the data $\left(\chi^{2}=575.64, p<.001\right.$; $\mathrm{RMSEA}=.06 ; \mathrm{CFI}=.93 ; \mathrm{TLI}=.92$; and $\mathrm{SRMR}=.05)$.

The corresponding structural model also resulted in a good fit with the data $\left(\chi^{2}=589.87, p<.001 ; \mathrm{RMSEA}=.06\right.$; $\mathrm{CFI}=.93 ; \mathrm{TLI}=.92$; and $\mathrm{SRMR}=.05)$ and is depicted in Figure 2. In addition, we also tested an alternative model where all non-hypothesized structural paths from autonomy supportive leadership and controlling leadership to job demands and job resources were specified. The alternative model did not provide a significantly better fit than our hypothesized model $\left(\chi^{2}=582.44, p<.001\right.$; RMSEA $=.06$; $\mathrm{CFI}=.93 ; \mathrm{TLI}=.92 ;$ and $\mathrm{SRMR}=.05 ; \Delta \chi^{2}=7.43$, $\mathrm{df}=3$, $p=.06)$.

Hypothesis testing. First, we investigated the relationships between autonomy supportive and controlling leadership with job resources and job demands, respectively (see Table 2). A positive association was found between autonomy supportive leadership and job resources $(\beta=0.50$, $\left.\mathrm{CI}_{95}=[0.36,0.62]\right)$, and controlling leadership and job demands $\left(\beta=0.64, \mathrm{CI}_{95}=[0.49,0.82]\right)$.

Then, we checked for the mediating effect of job resources on the relationship between autonomy supportive leadership and work engagement. Job resources mediated the relationship between autonomy supportive leadership and work engagement (indirect effect; $\beta=0.22, \mathrm{CI}_{95}=[0.12$, $0.35])$. The corresponding total effect $\left(\beta=0.37, \mathrm{CI}_{95}=[0.27\right.$, $0.47])$ and direct effects $\left(\beta=0.16, \mathrm{CI}_{95}=[0.01,0.31]\right)$ were also found to be significant. Job resources also mediated the relationship between autonomy supportive leadership and exhaustion (indirect effect; $\beta=-0.11, \mathrm{CI}_{95}=[-0.22$, $-0.04])$, albeit the corresponding total $\left(\beta=-0.07, \mathrm{CI}_{95}=[-\right.$ $0.21,0.07])$ and direct effects $\left(\beta=0.04, \mathrm{CI}_{95}=[-0.13,0.20]\right)$ failed to reach statistical significance (Zhao et al., 2010). Thus, results supported our first hypothesis and revealed that while job resources mediated the positive relationship between autonomy supportive leadership and work engagement, they also mediated the negative relationship between autonomy supportive leadership and exhaustion.

Support was also found for Hypothesis 2 as job demands mediated the relationship between controlling leadership and exhaustion (indirect effect; $\beta=0.28, \mathrm{CI}_{95}=[0.13,0.81]$ ). Although the direct effect $\left(\beta=-0.04, \mathrm{CI}_{95}=[-0.43,0.21]\right)$ of controlling leadership on exhaustion was not found to be 


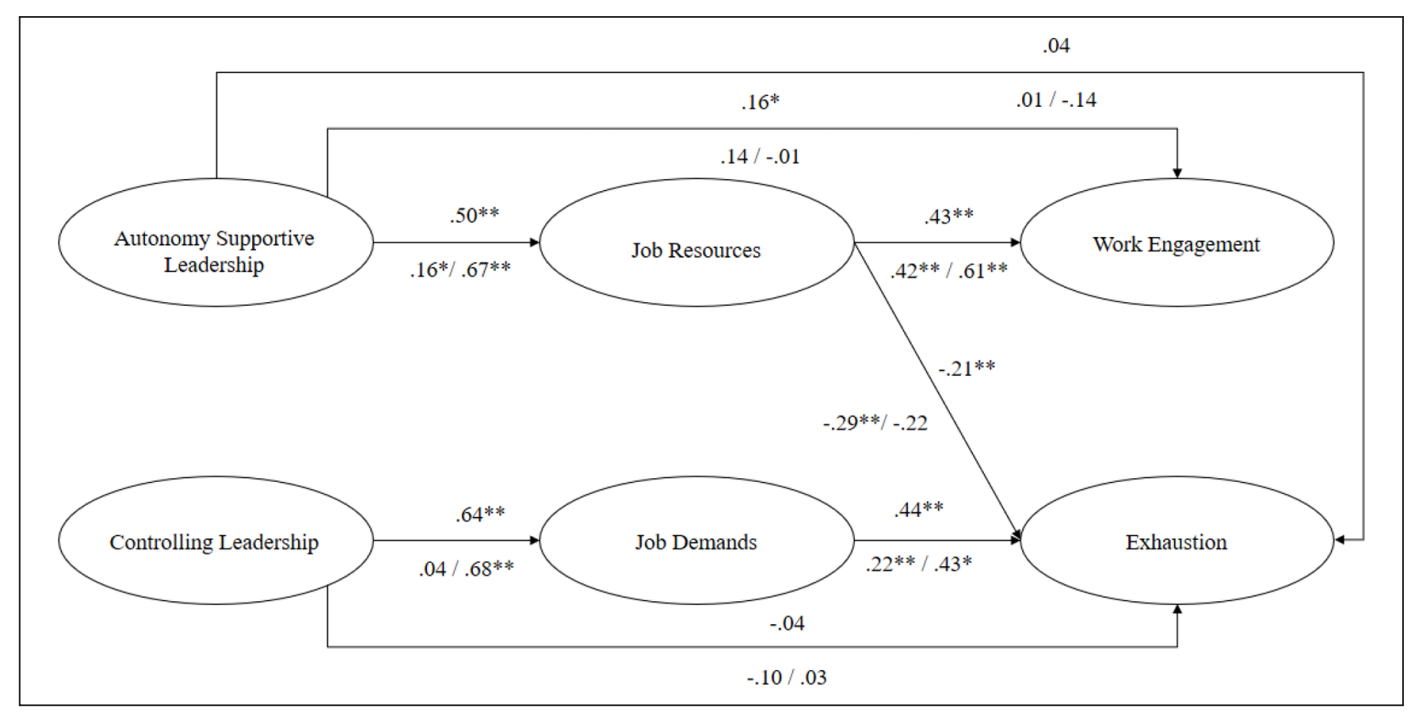

Figure 2. Standardized path coefficients of the structural equation models.

Above are the results from Study I (between-person) and below are the results from Study 2 (within-person/between-person).

significant, the corresponding total effect $(\beta=0.24$, $\left.\mathrm{CI}_{95}=[0.08,0.41]\right)$ reached statistical significance.

\section{Study 2}

\section{Method}

Participants and procedure. For Study 2, we collected data over a span of five consecutive working days in February 2020. Participants were recruited via the online platform LinkedIn to take part in a larger survey on employee wellbeing. One hundred and twenty-three white-collar employees were included in the study. All of them had one direct supervisor at their workplace. Participation was voluntary and anonymous, and informed consent was obtained from all participants. Participants were invited to take part in the daily survey in the early afternoon with the request to fill it out before the end of their working day. Ninety-one employees completed the questionnaire on more than one day. There were more female than male participants $(61.4 \%$ vs $38.6 \%)$ and their ages ranged from 22 to 62 years $(M=40.2$, $S D=11.6)$. The sample included employees working in the service sector $(55.4 \%)$, manufacturing $(28.9 \%)$, government $(7.2 \%)$, and health care $(8.4 \%)$. The majority of the sample had obtained higher education degrees $(36.1 \%$ at the master's level and $42.2 \%$ at the professional level), while the rest of the sample had obtained secondary education.

Measures. Participants had to report on how they experienced their leader, work design, and well-being on a specific day. To assess these daily experiences, we generally used slightly shorter scales of well-validated measures.

Daily autonomy supportive and controlling leadership. Daily autonomy supportive leadership was measured using five items (i.e., "Today, I felt that my manager had provided me with choices and options," "Today, I felt understood by my manager," "Today, my manager conveyed confidence in my ability to do my job well," "Today, my manager encouraged me to ask questions," and "Today my manager listened to how I would do things") from Baard et al. (2004). Daily controlling leadership style was measured using four items (i.e., "revealed my previous mistakes when he/she evaluated my work," "was less friendly to me when I didn't see things the way he/she sees them," "wanted to have control over my tasks," and "often interrupted me"), each of which were preceded with the stem "today, my leader." Unlike Study 1, in Study 2, we used the item "often interrupted me" from Barber (1996) instead of "is demanding and strict," as it seemed more appropriate for the daily context. ${ }^{2}$ Respondents indicated the degree to which they agreed with the items of autonomy supportive and controlling leadership on a scale from 1 ("totally disagree") to 5 ("totally agree").

Daily job demands. Daily job demands were measured with three items of emotional demands (e.g., "Today, my work was emotionally demanding") from Notelaers et al. (2007) and three items of role conflict (e.g., "Today, I had to deal with conflicting rules or orders") from Hansez (2001). Both job demands were measured using a 5-point Likert-type scale ranging from 1 ("totally disagree") to 5 ("totally agree").

Daily job resources. Daily job resources were measured using three items of autonomy (e.g., "Today, I could plan my work") from Rosenthal et al. (1996) and three items of learning opportunities (e.g., "Today, at work, I had the opportunity to further improve my skills") from Notelaers et al. (2007). A 5-point Likert-type scale ranging from 1 ("totally disagree") to 5 ("totally agree") was used to measure both job resources. 
Table 2. Mediation models of Study I predicting work engagement and burnout from autonomy supportive and controlling leadership, mediated by job resources and job demands.

\begin{tabular}{|c|c|c|c|c|c|c|}
\hline & \multicolumn{3}{|c|}{ Alternative model } & \multicolumn{3}{|c|}{ Hypothesized model } \\
\hline & $B$ & SE & $\mathrm{Cl}^{\mathrm{a}}$ & B & SE & $\mathrm{Cl}^{\mathrm{a}}$ \\
\hline \multicolumn{7}{|l|}{ Predictor on mediator } \\
\hline ASL $\rightarrow$ Job resources & $0.55^{* *}$ & 0.08 & {$[0.38,0.69]$} & $0.50 * *$ & 0.07 & {$[0.36,0.62]$} \\
\hline $\mathrm{CL} \rightarrow$ Job resources & 0.07 & 0.08 & {$[-0.07,0.22]$} & & & \\
\hline ASL $\rightarrow$ Job demands & 0.05 & 0.11 & {$[-0.16,0.29]$} & & & \\
\hline $\mathrm{CL} \rightarrow$ Job demands & $0.68 * *$ & 0.14 & {$[0.42,0.95]$} & $0.64 * *$ & 0.09 & {$[0.49,0.82]$} \\
\hline \multicolumn{7}{|l|}{ Mediator on outcome } \\
\hline Job resources $\rightarrow$ W Eng & $0.45 * *$ & 0.08 & {$[0.32,0.62]$} & $0.43 * *$ & 0.08 & {$[0.29,0.59]$} \\
\hline Job resources $\rightarrow$ Exhaustion & $-0.22 * *$ & 0.07 & {$[-0.39,-0.10]$} & $-0.21 * *$ & 0.07 & {$[-0.37,-0.09]$} \\
\hline Job demands $\rightarrow$ Exhaustion & $0.46 * *$ & 0.32 & {$[0.23,1.14]$} & $0.44 * *$ & 0.23 & {$[0.23,0.93]$} \\
\hline \multicolumn{7}{|l|}{ Direct effects } \\
\hline $\mathrm{ASL} \rightarrow \mathrm{W}$ Eng & 0.06 & 0.09 & {$[-0.13,0.23]$} & $0.16 *$ & 0.08 & {$[0.0 \mathrm{I}, 0.3 \mathrm{I}]$} \\
\hline ASL $\rightarrow$ Exhaustion & 0.04 & 0.12 & {$[-0.16,0.22]$} & 0.04 & 0.08 & {$[-0.13,0.20]$} \\
\hline $\mathrm{CL} \rightarrow \mathrm{W}$ Eng & -0.16 & 0.08 & {$[-0.32,0.01]$} & & & \\
\hline $\mathrm{CL} \rightarrow$ Exhaustion & -0.05 & 0.34 & {$[-0.67,0.22]$} & -0.04 & 0.22 & {$[-0.43,0.21]$} \\
\hline \multicolumn{7}{|l|}{ Indirect effects } \\
\hline ASL $\rightarrow$ Job Resources $\rightarrow$ W Eng & $0.25 * *$ & 0.07 & {$[0.14,0.42]$} & $0.22 * *$ & 0.06 & {$[0.12,0.35]$} \\
\hline ASL $\rightarrow$ Job Resources $\rightarrow$ Exhaustion & $-0.12 * *$ & 0.05 & {$[-0.25,-0.05]$} & $-0.11 * *$ & 0.05 & {$[-0.22,-0.04]$} \\
\hline ASL $\rightarrow$ Job Demands $\rightarrow$ Exhaustion & 0.02 & 0.10 & {$[-0.06,0.25]$} & & & \\
\hline $\mathrm{CL} \rightarrow$ Job Resources $\rightarrow$ W Eng & 0.03 & 0.04 & {$[-0.03,0.12]$} & & & \\
\hline $\mathrm{CL} \rightarrow$ Job Resources $\rightarrow$ Exhaustion & -0.02 & 0.02 & {$[-0.07,0.01]$} & & & \\
\hline $\mathrm{CL} \rightarrow$ Job Demands $\rightarrow$ Exhaustion & $0.31 * *$ & 0.33 & {$[0.12,1.08]$} & $0.28 * *$ & 0.21 & {$[0.13,0.81]$} \\
\hline \multicolumn{7}{|l|}{ Total effects } \\
\hline ASL $\rightarrow$ Work Engagement & $0.30 * *$ & 0.07 & {$[0.16,0.44]$} & $0.37^{* *}$ & 0.05 & {$[0.27,0.47]$} \\
\hline ASL $\rightarrow$ Exhaustion & -0.06 & 0.07 & {$[-0.21,0.08]$} & -0.07 & 0.07 & {$[-0.21,0.07]$} \\
\hline $\mathrm{CL} \rightarrow$ Work Engagement & -0.12 & 0.09 & {$[-0.30,0.05]$} & & & \\
\hline $\mathrm{CL} \rightarrow$ Exhaustion & $0.25 * *$ & 0.09 & {$[0.08,0.42]$} & $0.24 * *$ & 0.08 & {$[0.08,0.4 I]$} \\
\hline
\end{tabular}

ASL: autonomy supportive leadership; B: estimated parameter; CL: controlling leadership; Cl: confidence interval; SE=standard error; W Eng: work engagement.

$N=50$ I individuals. All coefficients are standardized coefficients.

a Lower and upper limit of the $95 \%$ confidence interval.

$*$ Significant at $95 \% \mathrm{Cl}$.

$* *$ Significant at $99 \% \mathrm{Cl}$.

Daily work engagement and exhaustion. The 3-item Ultra-Short Measure for Work Engagement (Schaufeli et al., 2019) was used to measure daily work engagement. It included items such as "Today, at my work, I feel bursting with energy." To measure daily exhaustion we used Schaufeli and Van Dierendonck's (2000) scale, albeit with a shorter selection of three items such as "Today, I felt emotionally drained from my work." A 5-point Likerttype scale ranging from 1 ("totally disagree") to 7 ("totally agree") was used to record responses on both scales.

\section{Analyses}

The entire model was estimated by specifying all paths mentioned in Figure 1. Given the hierarchical data structure, we used a multilevel structural equation modeling framework in Mplus 8 (Mplus Version 8, Muthén \& Muthén, 2017) and followed Preacher et al.'s (2010, 2011) recommendations for testing a multilevel mediation model. Analytical models were specified at the within-person and between-person level simultaneously corresponding to person-mean centering of predictor variables at the withinperson level. We used a parametric bootstrap procedure to produce $95 \%$ confidence intervals around parameter estimates to account for the asymmetric nature of the sampling distribution of the indirect effects.

\section{Results}

Descriptive statistics and model fit. The means, standard deviations, omega reliabilities, and correlations among the study variables are shown in Table 3 . To confirm the distinctiveness of our predictor, mediator, and outcome variables, we conducted a multilevel CFA including autonomy supportive leadership, controlling leadership, job demands, job resources, work engagement, and exhaustion. The 
Table 3. Means, standard deviations, and correlations among the study variables of Study 2.

\begin{tabular}{|c|c|c|c|c|c|c|c|c|c|c|c|}
\hline & & $M$ & $S D$ & I & 2 & 3 & 4 & 5 & 6 & 7 & 8 \\
\hline I & ASL & 3.59 & 0.77 & {$[.81, \overline{96}]$} & -.04 & .04 & $-.16 *$ & .08 & $.17^{* *}$ & $.21 * *$ & -.06 \\
\hline 2 & $C L$ & 1.75 & 0.65 & $-.45 * * *$ & {$[.68, \overline{.95}]$} & .01 & .06 & $-.19 * *$ & .06 & -.09 & -.06 \\
\hline 3 & Emotional demands & 1.94 & 0.66 & -.17 & $.47 * * *$ & {$[.59, \overline{.96}]$} & $.38 * * *$ & $-.14^{*}$ & .07 & -.12 & $.24 * *$ \\
\hline 4 & Role conflict & 2.36 & 0.72 & $-.22 *$ & $.51 * * *$ & $.6 I^{* * *}$ & {$[.63, \overline{90}]$} & $-.19 * *$ & -.07 & $-.24 * *$ & $.21 * *$ \\
\hline 5 & Autonomy & 4.15 & 0.71 & $.5 I * * *$ & $-.49 * * *$ & -.15 & $-.26 *$ & {$[.80, \overline{97}]$} & $.14 *$ & $.31 * * *$ & $-.24 * *$ \\
\hline 6 & Learning Opportunities & 3.40 & 0.84 & $.45 * * *$ & $-.29 * *$ & .03 & .13 & $.42 * * *$ & {$[.77, \overline{99}]$} & $.35 * * *$ & $-.23 * *$ \\
\hline 7 & Work Engagement & 3.63 & 0.70 & $.34 * *$ & $-.28 * *$ & .09 & .00 & $.4 I^{* * *}$ & $.54 * * *$ & {$[.73, \overline{93}]$} & $-.26 * * *$ \\
\hline 8 & Exhaustion & 2.39 & 0.75 & $-.36 * * *$ & $.41 * * *$ & $.45^{* * *}$ & $.39 * * *$ & $-.38 * * *$ & $-.28^{* *}$ & $-.31^{* *}$ & {$[.84, \overline{98}]$} \\
\hline
\end{tabular}

SD: standard deviation; ASL: autonomy supportive leadership; CL: controlling leadership.

$\mathrm{N}=9 \mathrm{I}$ individuals and 358 observations. Within-person correlations are depicted above the diagonal; between-level correlations for the Level

I correlations were computed and aggregated to the person level. On the diagonal, the within and between Omega reliability coefficients are reported.

$*_{p}<.05$.

$* * p<.01$.

$* * * p<.001$.

items of these constructs loaded onto their respective factors at the within- and between-person levels of analysis, respectively. All factors were allowed to correlate with each other. The measurement model resulted in a good fit, $\chi^{2}=418.98, p<.001 ; \mathrm{CFI}=.94 ; \mathrm{TLI}=.93 ; \mathrm{RMSEA}=.04$; SRMR $($ within $)=.05$; SRMR $($ between $)=.08$.

In estimating the structural model, we used the scale means of learning opportunities and job autonomy as indicators of job resources, and the scale means of role conflict and emotional demands as indicators of job demands. The other variables (i.e., autonomy supportive leadership, controlling leadership, work engagement, and exhaustion) were measured with their respective items. The corresponding structural model also resulted in a good fit with the data, $\chi^{2}=22.17, p<.05 ; \mathrm{RMSEA}=.06 ; \mathrm{CFI}=.94$; $\mathrm{TLI}=.83$; and SRMR (within and between) $=.06$, and is depicted in Figure 2. In addition, similar to Study 1, we tested an alternative model where all non-hypothesized structural paths from autonomy supportive leadership and controlling leadership to job demands and job resources were specified at the within- and between-person levels. The alternative model did not provide a significantly better fit than our hypothesized model, $\chi^{2}=16.06, p<.01$; RMSEA $=.06$; $\mathrm{CFI}=.95$; TLI $=.59$; and SRMR (within and between $)=.05 ; \Delta \chi^{2}=6.95, \mathrm{df}=6, p=.33$.

Hypothesis testing. To estimate the relative amount of between- and within-person variance, we estimated intraclass coefficients (ICC1). An inspection of intra-class coefficients (ICC1) revealed that within-person variability accounted for $41 \%$ variance in autonomy supportive leadership, $39 \%$ variance in controlling leadership, $38 \%$ variance in job resources, $44 \%$ variance in job demands, $43 \%$ variance in work engagement, and $49 \%$ variance in exhaustion.

Within-person analysis. First, we investigated the relationships between autonomy supportive and controlling leadership with job resources and job demands (see Table 4).
Autonomy supportive leadership was positively related to job resources $\left(\beta=0.16, \mathrm{CI}_{95}=[0.04,0.29]\right)$. Contrary to expectations, controlling leadership was found to be unrelated to job demands $\left(\beta=0.04, \mathrm{CI}_{95}=[-0.11,0.19]\right)$.

Results of the multilevel mediation model for work engagement are depicted in Table 4. In line with Hypothesis 1 , job resources mediated the relationship between autonomy supportive leadership and work engagement (indirect effect; $\left.\beta=0.07, \mathrm{CI}_{95}=[0.02,0.12]\right)$. The corresponding total effect was found to be significant $\left(\beta=0.21, \mathrm{CI}_{95}=[0.04\right.$, $0.37])$, although the direct effect $\left(\beta=0.14, \mathrm{CI}_{95}=[-0.01\right.$, $0.28]$ ) of autonomy supportive leadership on work engagement failed to reach statistical significance. Job resources did not mediate the relationship between autonomy supportive leadership and exhaustion as the direct $\left(\beta=0.01, \mathrm{CI}_{95}=[-\right.$ $0.10,0.11])$, indirect $\left(\beta=-0.05, \mathrm{CI}_{95}=[-0.10,0.01]\right)$, and total $\left(\beta=-0.04, \mathrm{CI}_{95}=[-0.15,0.07]\right)$ effects failed to reach statistical significance. In conclusion, these results show that Hypothesis 1 was only partially supported.

Hypothesis 2 was not supported as job demands did not mediate the relationship between controlling leadership and exhaustion (indirect effect; $\beta=0.01, \mathrm{CI}_{95}=[-0.02$, $0.04])$. We also did not find significant direct $(\beta=-0.10$, $\left.\mathrm{CI}_{95}=[-0.23,0.03]\right)$ and total effects $\left(\beta=-0.09, \mathrm{CI}_{95}=[-\right.$ $0.23,0.05])$ of controlling leadership on exhaustion.

Between-person analysis. All the effects at the between-person level in Study 2 were comparable to that of Study 1 except that the hypothesized negative relationship between autonomy supportive leadership and exhaustion via job resources, and the direct effect of autonomy supportive leadership on work engagement were not significant (see Table 4).

\section{Discussion}

The aim of this research was to explore and compare how autonomy supportive and controlling leadership styles relate to job resources and job demands and - therefore- to 


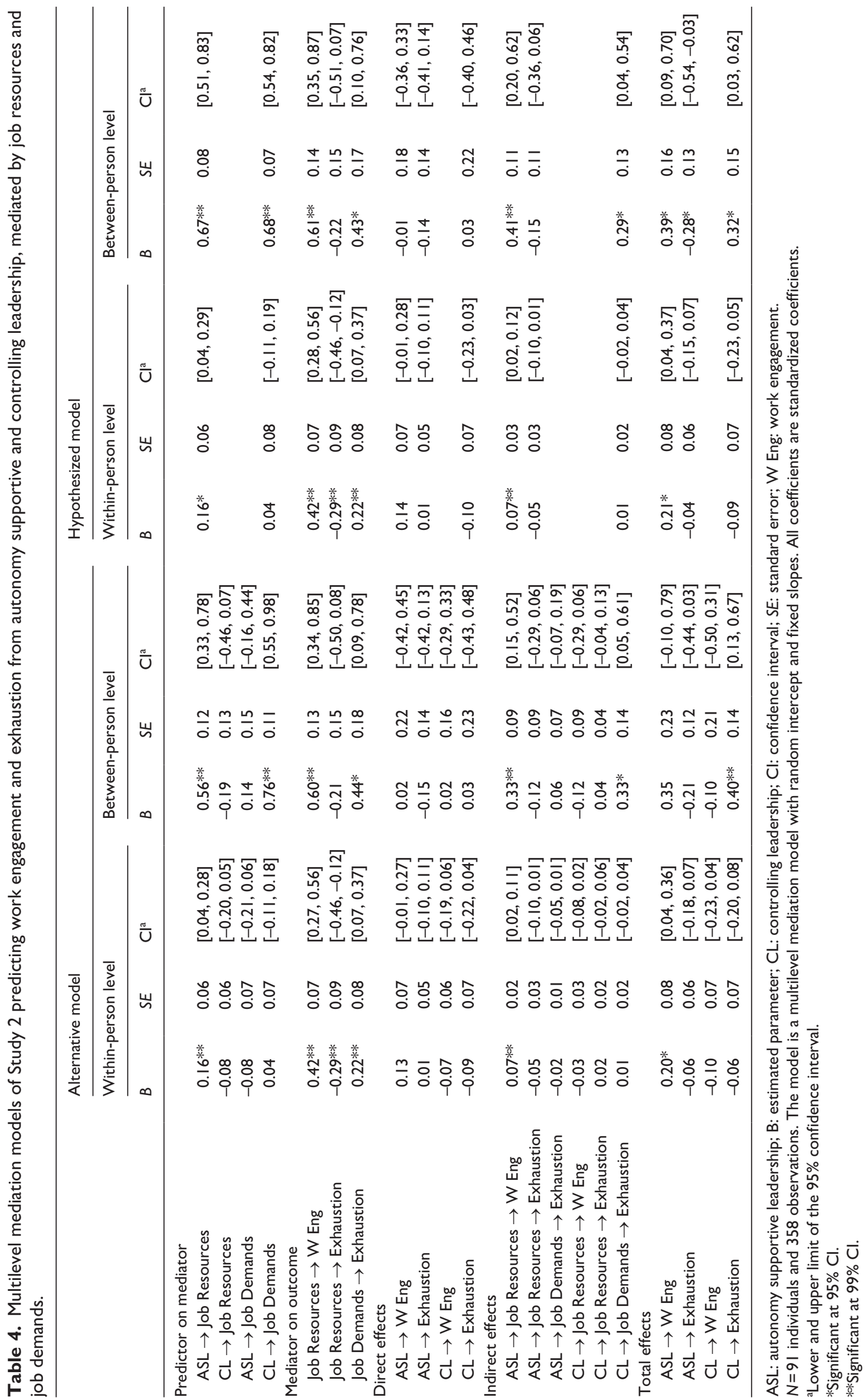


employee well-being. A cross-sectional study and a complementary daily diary study were done to test our hypotheses at the between- and within-person levels.

As respects autonomy supportive leadership, work design, and employee well-being, our results consistently showed that autonomy supportive leadership relates to work engagement via job resources. In doing so, our research supports the premise of SDT (Deci \& Ryan, 2000; Gagné \& Deci, 2005) and solidifies extant literature (Slemp et al., 2018) by showing that, when leaders provide autonomy support (i.e., take interest in employees' perspectives, offer choices, and give meaningful rationales when choice is not possible), employees tend to feel well. Next to supporting its tenets, our findings also advance SDT by highlighting that the positive association between autonomy supportive leadership (a social aspect of work) and employees' work engagement is mediated by work design (a structural aspect of work). We thus provide insights into the relationship between different sources (i.e., social and structural) of work motivation and elucidate a process by which autonomy supportive leaders may support employee well-being.

Notably, our results also advance the literature on antecedents of work design (Parker et al., 2019; Parker, Van den Broeck, \& Holman, 2017) and the JDR model (Demerouti et al., 2001). So far, scholars have only examined autonomy supportive leadership as an antecedent of job crafting (Slemp et al., 2015), which is a bottom-up approach to the work design process (Parker, Van den Broeck, \& Holman, 2017). Based on our findings, we inform work design scholars that the positive link between autonomy supportive leadership and employees' perceived job resources could also indicate a top-down effect of autonomy supportive leadership in creating (perceptions of) work design. Specifically, our results showed that autonomy supportive leadership may serve as antecedents to the motivational aspects of work design that is, job resources, to foster work engagement. As such, our results add to the literature where several positive types of leadership have been found to be associated with an increase in (perceptions of) resourceful job designs (e.g., Fernet et al., 2015; Rahmadani et al., 2020).

Moreover, our results also indicate that such associations may emerge both at a general level between individuals and in individuals' daily experiences. This implies that (1) in general, it can be expected that employees of autonomy supportive leaders would tend to feel more resourceful and engaged at work than employees who do not receive autonomy support from their leaders, and (2) when leaders adopt an autonomy supportive leadership style, they may expect to see a related increase in their employees' perceptions of job resources and work engagement in the same day. This suggests that the positive association between autonomy supportive leadership and employee well-being via work design may emerge rather immediately. Note, however, that, in our diary data, the effect of autonomy supportive leadership on job resources was found to be smaller at the within-person level than at the between-person level.

Our findings are particularly interesting to the scant literature on leadership and positive employee well-being. Previous research on this topic has been criticized for lacking conceptual alignment between leadership styles, mediators, and positive well-being criteria (Inceoglu et al., 2018). Our research overcomes this issue by linking a solely motivation-based leadership style (i.e., autonomy supportive leadership) to motivational aspects of work design (i.e., job resources) and employee well-being (i.e., work engagement). Thus, our research provides theoretically coherent insights on the link between leadership styles and positive employee well-being via work design.

When it comes to preventing negative well-being, we found inconsistent evidence for autonomy supportive leadership offsetting unhealthy consequences such as exhaustion via job resources. While our hypothesis was supported by the between-person analysis of Study 1, the within- and between-person analysis of Study 2 failed to confirm this line of thinking. In Study 2, at the withinperson level, the path from autonomy supportive leadership to job resources and the path from job resources to exhaustion were found to be significant in the expected direction. Yet, given that the relationship between autonomy supportive leadership and job resources was relatively small, we did not find statistically significant evidence for the expected indirect effect. Daily experiences of autonomy support from leaders may thus be insufficient to offset employees' feelings of exhaustion via job resources on the same day.

Also at the between-person level in Study 2, the association between autonomy supportive leadership and exhaustion via job resources was not found to be significant, as there was no relationship between job resources and exhaustion. From a methodological perspective, we may speculate that the insignificant findings in Study 2 could be due to the relatively low sample size and statistical power of our diary study. It is, however, interesting to note that theoretically, the original JDR model did not stipulate a negative relationship between job resources and exhaustion. Yet, some scholars (e.g., Schaufeli \& Bakker, 2004) and research evidence (e.g., Lesener et al., 2019) support such a relationship. In light of such ongoing debate, our divergent results may suggest that the relationship between job resources and negative well-being merits further attention. Future research may want to examine whether this relationship (1) is weak at best and hence requires a relatively big sample size to emerge or (2) may only arise for particular job resources and forms of negative well-being (e.g., burnout vs exhaustion). Such empirical research may then further inform theorizing in the realm of JDR. For now, we conclude that although we found some evidence for the health-improving influence 
of autonomy supportive leadership via job resources, the evidence is weak and tentative at best.

With respect to controlling leadership, work design, and employee well-being, results of the between-subject analyses of Study 1 and Study 2 showed that controlling leadership associates positively with employees' exhaustion via job demands. Expounding on the association between leader control and employee well-being, SDT states that, when leaders restrict the locus of control to themselves they induce controlled motivation which leads to subsequent negative health consequences among followers. Research stemming from SDT show that, indeed, perceived leader control associates negatively with negative forms of employee well-being, such as anxiety, depression, and negative affect (Moreau \& Mageau, 2012). Our results further solidify such research by highlighting that, in general, when leaders resort to controlling leadership, their employees tend to feel more exhausted at work. Our findings also contribute to the extant literature by highlighting that the positive association between controlling leadership and employee ill-being manifests via health-impairing aspects of work design such as job demands. Given that there is a paucity of research examining how negative leadership styles relate to employee well-being (Inceoglu et al., 2018), our findings provide some interesting insights from a work design perspective.

It is, however, noteworthy that in our study these relationships did not emerge in employees' day-to-day experiences. The incongruence between the general association and day-to-day association of controlling leadership with job demands and employee well-being could be because job demands often act as 'givens' - that is, aspects that are inherent to the work situation and hence relatively less pervious to change by contextual factors (Hakanen et al., 2006). Hakanen et al. (2006) state that, unlike the relatively unchanging job demands, job resources tend to be more malleable and thus more easily "alterable." A comparative evaluation of our results advances this JDR narrative by showing that while job resources are positively influenced by variations in autonomy supportive leadership both at the within- and between-person levels, variations in job demands are related to variations in controlling leadership only when averaged across individuals, and not in day-to-day experiences. These findings also contribute to the literature by highlighting the differences in how autonomy supportive and controlling leadership styles may serve as different antecedents of job resources and job demands, respectively.

\section{Motivation fostering socio-structural aspects of work: keys to workplace re-enchantment}

All in all, our research suggests that social aspects of work such as leadership often tend to be associated with structural aspects of work such as work design.
Furthermore, when both these aspects foster autonomous rather than controlled motivation among employees, they positively contribute to employees' well-being at work. Given that there was a 13-year time difference between our two studies, our most consistent finding evidences that the connections among autonomous motivation fostering socio-structural workplace factors (i.e., autonomy supportive leadership and job resources) and employee well-being seem to hold and maintain relevance despite inevitable changes in workplace dynamics. This could be because autonomy supportive leadership and job resources foster employees' self-determination, in addition to promoting immediate positive outcomes such as work engagement (Deci \& Ryan, 2000; Gagné \& Deci, 2005). They therefore also contribute to the satisfaction of more innate and basic psychological needs that are inherent to being human (Van den Broeck et al., 2008). When it comes to advancing scholarship that seeks to reenchant dehumanized workplaces that deprive human agency (Al-Amoudi, 2019), our research provides some valuable insights. Our findings suggest that when leaders actively endorse employees' self-determination instead of enforcing control, they may foster employees' resource perceptions and consequently also their well-being.

\section{Practical implications}

This article also provides some important insights for practitioners. In the workplace setting, adopting direct interventions to change job characteristics may not always be feasible (Fernet et al., 2015). For such situations, our findings can provide some insights into alternative solutions such as furthering employees' work design by training leaders to be autonomy supportive.

Our research, however, was unable to rule out whether only perceptions of work design are changed or whether leaders may also influence actual work design of employees. However, meta-analytic results show that changing perceptions of work characteristics are as effective in influencing employees' well-being as objective changes to work design (Fried \& Ferris, 1987). We therefore feel confident to suggest that managers can expect to see related changes in employees' work design as well as well-being, when they adopt an autonomy supportive leadership style.

Given the benefits associated with autonomy supportive leadership, organizations could work toward orienting leadership trainings to promote autonomous rather than controlled motivation. Doing so could eventually facilitate positive changes in structural aspects of work (e.g., highquality work designs with enhanced job resources) and contribute to employee well-being. Such interventions would ideally take place next to the implementation of compatible organizational practices (e.g., HR practices). Integrating efforts thus could help in re-enchanting workplaces to foster sustainable organizational development 
through the effective management of people and their potential (Pfeffer, 1995).

\section{Limitations and future research}

Alongside its contributions, it is also important to acknowledge the limitations of our studies. First, in both our studies, we examined the associations of autonomy supportive and controlling leadership with employees' work designs by using only a limited set of job demands and job resources. Moreover, the two job demands studied in this research (i.e., emotional demands and role-conflict) are known to be hindrance demands as they generally have a negative and distressing effect on employee well-being (Van den Broeck et al., 2010). Given that certain job demands - labeled as job challenges - such as workload, cognitive demands, and time pressures, can also have a positive and stimulating effect on employees (Van den Broeck et al., 2010), future research should examine the generalizability of our findings by examining such challenging job demands along with other job resources such as task identity and task significance. Moreover, in extending our findings, future research could also rely on other relevant scales - such as the one by Moreau and Mageau (2012) - for measuring autonomy supportive, and especially controlling leadership, as using different instruments to measure constructs can help confirm the generalizability of results across multiple operationalizations.

Second, even though this research extended beyond cross-sectional investigations and examined relationship patterns at both within- and between-person levels, its findings were based only on correlational data, which limits causal inference. Therefore, it could be interesting to replicate our findings through longitudinal experiments. In that regard, an interesting example could be the study of Sanchez-Manzanares et al. (2020), who manipulated directive and empowering leadership styles through selection and training, and observed their effects on team performance on a computer-based simulation task. Alternatively, future research could also examine whether interventions to increase leader autonomy support (e.g., Deci et al., 1989) could lead to changes in the (perceptions of) work design among employees.

Third, since this research relied on cross-sectional data which can be susceptible to common method variance, and more importantly, are not optimal for testing mediation models, we encourage future research to further solidify our findings by examining our hypotheses using longitudinal mediation designs. Moreover, although leaders are known to make objective changes to employees' work designs (Parker, Van den Broeck, \& Holman, 2017), in this article we only measured changes to job demands and job resources as rated by the employees themselves. Therefore, future research could rely on more objective measures of job demands, job resources, and employee well-being to further solidify our findings.
Fourth, in this article, we did not study contextual factors such as organizational culture which could help in explaining the inconsistencies between the results of the within-person and between-person analysis. Deci et al. (1989) highlighted that autonomy support may not have its expected positive effects on employees when the organizational culture or climate is, for example, unsupportive of employee participation. Therefore, additional research accounting for such organization level variables could help in highlighting important nuances.

Furthermore, although we made a novel contribution to the work design literature by introducing the concept of controlling leadership and examining its effects on employees' work design and well-being, we ought to acknowledge that controlling leadership is only one form of negatively oriented leadership style. Therefore, future research may carry forward this line of investigation by examining whether other counterproductive leadership styles (e.g., petty tyranny and destructive leadership) could also influence employees' well-being via work design. Finally, although for the purpose of this study we examined the effects of controlling leadership and autonomy supportive leadership separately, in reality leaders may adopt both leadership styles in conjunction (Haerens et al., 2018). Therefore, future research may use techniques like profile analysis to examine the effects of all possible combinations of autonomy supportive and controlling leadership styles.

\section{Acknowledgements}

We would like to thank Hans Tierens for his helpful comments and suggestions on data analysis.

\section{Declaration of conflicting interests}

The author(s) declared no potential conflicts of interest with respect to the research, authorship, and/or publication of this article.

\section{Funding}

The author(s) received no financial support for the research, authorship, and/or publication of this article.

\section{ORCID iD}

Pallavi Sarmah (iD https://orcid.org/0000-0002-6590-4495

\section{Notes}

1. The measures of autonomy supportive leadership and controlling leadership used in this study were found to converge with other measures of these leadership styles and have predictive validity with employee motivation (see Appendix 1).

2. The measures of autonomy supportive and controlling leadership used in this study were found to converge with other measures of these leadership styles and have predictive validity with employee motivation (see Appendix 1). 


\section{References}

Aasland, M. S., Skogstad, A., Notelaers, G., Nielsen, M. B., \& Einarsen, S. (2010). The prevalence of destructive leadership behaviour. British Journal of Management, 21(2), 438-452.

Aelterman, N., Vansteenkiste, M., Haerens, L., Soenens, B., Fontaine, J. R., \& Reeve, J. (2019). Toward an integrative and fine-grained insight in motivating and demotivating teaching styles: The merits of a circumplex approach. Journal of Educational Psychology, 111(3), 497-521.

Al-Amoudi, I. (2019). Management and de-humanization in late modernity. In I. Al-Amoudi \& J. Morgan (Eds.), Realist Responses to Post-Human Society: Ex Machina (pp. 182194). Routledge.

Anderson, J. C., \& Gerbing, D. W. (1988). Structural equation modeling in practice: A review and recommended two-step approach. Psychological Bulletin, 103(3), 411-423.

Ashforth, B. (1994). Petty tyranny in organizations. Human Relations, 47(7), 755-778.

Baard, P. P., Deci, E. L., \& Ryan, R. M. (2004). Intrinsic need satisfaction: A motivational basis of performance and well-being in two work settings. Journal of Applied Social Psychology, 34(10), 2045-2068.

Baillien, E., De Cuyper, N., \& De Witte, H. (2011). Job autonomy and workload as antecedents of workplace bullying: A two-wave test of Karasek's Job Demand Control Model for targets and perpetrators. Journal of Occupational and Organizational Psychology, 84(1), 191-208.

Bakker, A. B., \& Demerouti, E. (2007). The Job DemandsResources model: State of the art. Journal of Managerial Psychology, 22, 309-328.

Bakker, A. B., \& Demerouti, E. (2017). Job demands-resources theory: Taking stock and looking forward. Journal of Occupational Health Psychology, 22(3), 273-285.

Barber, B. K. (1996). Parental psychological control: Revisiting a neglected construct. Child Development, 67(6), 3296-3319.

Biessen, P. G. A., \& De Gilder, D. (1993). BASAM: BasisvragenlijstÚmsterdam: Handleiding [Manual BASAM Questionnaire]. Swets \& Zeitlinger.

Boje, D. M., \& Baskin, K. (2011). Our organizations were never disenchanted. Journal of Organizational Change Management, 24, 411-426.

Deci, E. L., Connell, J. P., \& Ryan, R. M. (1989). Selfdetermination in a work organization. Journal of Applied Psychology, 74(4), 580-590.

Deci, E. L., \& Ryan, R. M. (1987). The support of autonomy and the control of behavior. Journal of Personality and Social Psychology, 53(6), 1024-1037.

Deci, E. L., \& Ryan, R. M. (2000). The "what" and "why" of goal pursuits: Human needs and the self-determination of behavior. Psychological Inquiry, 11(4), 227-268.

Demerouti, E., Bakker, A. B., Nachreiner, F., \& Schaufeli, W. B. (2001). The job demands-resources model of burnout. Journal of Applied Psychology, 86(3), 499-512.

Fernet, C., Trépanier, S. G., Austin, S., Gagné, M., \& Forest, J. (2015). Transformational leadership and optimal functioning at work: On the mediating role of employees' perceived job characteristics and motivation. Work and Stress, 29(1), 11-31.

Fried, Y., \& Ferris, G. R. (1987). The validity of the job characteristics model: A review and meta-analysis. Personnel Psychology, 40(2), 287-322.
Gagné, M., \& Deci, E. L. (2005). Self-determination theory and work motivation. Journal of Organizational Behavior, 26(4), 331-362.

Gagné, M., Forest, J., Vansteenkiste, M., Crevier-Braud, L., Van den Broeck, A., Aspeli, A. K., Bellerose, J., Benabou, C., Chemolli, E., Güntert, S. T., Halvari, H., Indiyastuti, D. L., Johnson, P. A., Molstad, M. H., Naudin, M., Ndao, A., Olafsen, A. H., Roussel, P., Wang, Z., \& Westbye, C. (2015). The Multidimensional Work Motivation Scale: Validation evidence in seven languages and nine countries. European Journal of Work and Organizational Psychology, 24, 178-196.

Grant, A. M., \& Parker, S. K. (2009). Redesigning work design theories: The rise of relational and proactive perspectives. Academy of Management Annals, 3(1), 317-375.

Haerens, L., Vansteenkiste, M., De Meester, A., Delrue, J., Tallir, I., Vande Broek, G., \& Aelterman, N. (2018). Different combinations of perceived autonomy support and control: Identifying the most optimal motivating style. Physical Education and Sport Pedagogy, 23(1), 16-36.

Hakanen, J. J., Bakker, A. B., \& Schaufeli, W. B. (2006). Burnout and work engagement among teachers. Journal of School Psychology, 43(6), 495-513.

Hansez, I. (2001). La validation du WOCCQ: Vers un modèle structural du stress et du contrôle de l'activité de travail [The validation of WOCCQ: Towards a structural model of stress and the control of work activity] [Unpublished Doctoral dissertation, Université de Liège].

Hobfoll, S. E. (1989). Conservation of resources: A new attempt at conceptualizing stress. American Psychologist, 44(3), 513524.

Hodge, K., \& Lonsdale, C. (2011). Prosocial and antisocial behavior in sport: The role of coaching style, autonomous vs. controlled motivation, and moral disengagement. Journal of Sport and Exercise Psychology, 33(4), 527-547.

Howard, J. L., Gagné, M., Morin, A. J. S. S., \& Forest, J. (2018). Using bifactor exploratory structural equation modeling to test for a continuum structure of motivation. Journal of Management, 44(7), 2638-2664. https://doi. org/10.1177/0149206316645653

Hu, L. T., \& Bentler, P. M. (1999). Cutoff criteria for fit indexes in covariance structure analysis: Conventional criteria versus new alternatives. Structural Equation Modeling: $A$ Multidisciplinary Journal, 6(1), 1-55.

Inceoglu, I., Thomas, G., Chu, C., Plans, D., \& Gerbasi, A. (2018). Leadership behavior and employee well-being: An integrated review and a future research agenda. The Leadership Quarterly, 29(1), 179-202.

Jiang, Z., Di Milia, L., Jiang, Y., \& Jiang, X. (2020). Thriving at work: A mentoring-moderated process linking task identity and autonomy to job satisfaction. Journal of Vocational Behavior, 118(1), Article 103373.

Lesener, T., Gusy, B., \& Wolter, C. (2019). The job demandsresources model: A meta-analytic review of longitudinal studies. Work \& Stress, 33(1), 76-103.

Loosveldt, G., \& Beullens, K. (2017). Interviewer effects on nondifferentiation and straightlining in the European Social Survey. Journal of Official Statistics, 33(2), 409-426.

Mageau, G. A., Ranger, F., Joussemet, M., Koestner, R., Moreau, E., \& Forest, J. (2015). Validation of the perceived 
parental autonomy support scale (P-PASS). Canadian Journal of Behavioural Science/Revue canadienne des sciences du comportement, 47(3), 251-262.

Moreau, E., \& Mageau, G. A. (2012). The importance of perceived autonomy support for the psychological health and work satisfaction of health professionals: Not only supervisors count, colleagues too! Motivation and Emotion, 36(3), $268-286$

Muthén, L. K., \& Muthén, B. (2017). Mplus user's guide: Statistical analysis with latent variables. User's guide.

Nahrgang, J. D., Morgeson, F. P., \& Hofmann, D. A. (2011). Safety at work: A meta-analytic investigation of the link between job demands, job resources, burnout, engagement, and safety outcomes. The Journal of Applied Psychology, 96(1), 71-94.

Notelaers, G., De Witte, H., Van Veldhoven, M., \& Vermunt, J. (2007). Construction and validation of the short inventory to monitor psychosocial hazards. Arbeidsgezondheidszorg \& Ergonomie, 44, 11-17.

Ohly, S., Sonnentag, S., Niessen, C., \& Zapf, D. (2010). Diary studies in organizational research. Journal of Personnel Psychology, 9, 79-93.

Oldham, G. R., \& Fried, Y. (2016). Job design research and theory: Past, present and future. Organizational Behavior and Human Decision Processes, 136, 20-35.

Parker, S. K. (2014). Beyond motivation: Job and work design for development, health, ambidexterity, and more. Annual Review of Psychology, 65, 661-691.

Parker, S. K., Andrei, D. M., \& Van den Broeck, A. (2019). Poor work design begets poor work design: Capacity and willingness antecedents of individual work design behavior. Journal of Applied Psychology, 104(7), 907-928.

Parker, S. K., Morgeson, F. P., \& Johns, G. (2017). One hundred years of work design research: Looking back and looking forward. Journal of Applied Psychology, 102(3), 403-420.

Parker, S. K., Van den Broeck, A., \& Holman, D. (2017). Work design influences: A synthesis of multilevel factors that affect the design of jobs. Academy of Management Annals, 11(1), 267-308.

Pfeffer, J. (1995). Producing sustainable competitive advantage through the effective management of people. Academy of Management Perspectives, 9(1), 55-69.

Preacher, K. J., Zhang, Z., \& Zyphur, M. J. (2011). Alternative methods for assessing mediation in multilevel data: The advantages of multilevel SEM. Structural Equation Modeling, 18, 161-182.

Preacher, K. J., Zyphur, M. J., \& Zhang, Z. (2010). A general multilevel SEM framework for assessing multilevel mediation. Psychological Methods, 15, 209-233.

Rahmadani, V. G., Schaufeli, W. B., \& Stouten, J. (2020). How engaging leaders foster employees' work engagement. Leadership \& Organization Development Journal, 41(8), 1155-1169.

Reeve, J. (2009). Why teachers adopt a controlling motivating style toward students and how they can become more autonomy supportive. Educational Psychologist, 44(3), 159-175.

Reeve, J., Vansteenkiste, M., Assor, A., Ahmad, I., Cheon, S. H., Jang, H., \& Wang, C. K. J. (2014). The beliefs that underlie autonomy-supportive and controlling teaching: A multinational investigation. Motivation and Emotion, 38(1), 93-110.

Rosenthal, P., Guest, D., \& Peccei, R. (1996). Gender differences in managers' causal explanations for their work performance: A study in two organizations. Journal of Occupational and Organizational Psychology, 69(2), 145151.

Salancik, G. R., \& Pfeffer, J. (1978). A social information processing approach to job attitudes and task design. Administrative Science Quarterly, 23, 224-253.

Sanchez-Manzanares, M., Rico, R., Antino, M., \& Uitdewilligen, S. (2020). The joint effects of leadership style and magnitude of the disruption on team adaptation: A longitudinal experiment. Group \& Organization Management, 45(6), 836-864.

Schaufeli, W. B. (2015). Engaging leadership in the job demandsresources model. Career Development International, 20(5), 446-463.

Schaufeli, W. B. (2017). Applying the job demands-resources model: A "how to" guide to measuring and tackling work engagement and burnout. Organizational Dynamics, 46(2), 120-132.

Schaufeli, W. B., \& Bakker, A. B. (2004). Job demands, job resources, and their relationship with burnout and engagement: A multi-sample study. Journal of Organizational Behavior, 25, 293-315.

Schaufeli, W. B., Shimazu, A., Hakanen, J., Salanova, M., \& De Witte, H. (2019). An ultra-short measure for work engagement: The UWES-3 validation across five countries. European Journal of Psychological Assessment, 35(4), 577-591.

Schaufeli, W. B., \& Van Dierendonck, D. (2000). Utrechtse Burnoutschaal (UBOS), Handleiding [Manual of the Dutch Burnout Scale]. Swets and Zeitlinger.

Schyns, B., \& Schilling, J. (2013). How bad are the effects of bad leaders? A meta-analysis of destructive leadership and its outcomes. The Leadership Quarterly, 24(1), 138-158.

Shafer, S. L., \& Dexter, F. (2012). Publication bias, retrospective bias, and reproducibility of significant results in observational studies. Anesthesia \& Analgesia, 114(5), 931-932.

Slemp, G. R., Kern, M. L., Patrick, K. J., \& Ryan, R. M. (2018). Leader autonomy support in the workplace: A meta-analytic review. Motivation and Emotion, 42(5), 706-724.

Slemp, G. R., Kern, M. L., \& Vella-Brodrick, D. A. (2015). Workplace well-being: The role of job crafting and autonomy support. Psychology of Well-being, 5(1), 1-17.

Spector, P. E. (2019). Do not cross me: Optimizing the use of cross-sectional designs. Journal of Business and Psychology, 34(2), 125-137.

Taylor, F. W. (1911). The principles of scientific management. Harper.

Van den Broeck, A., De Cuyper, N., De Witte, H., \& Vansteenkiste, M. (2010). Not all job demands are equal: Differentiating job hindrances and job challenges in the job demands-resources model. European Journal of Work and Organizational Psychology, 19(6), 735-759.

Van den Broeck, A., Vansteenkiste, M., De Witte, H., \& Lens, W. (2008). Explaining the relationships between job characteristics, burnout, and engagement: The role of basic psychological need satisfaction. Work \& Stress, 22(3), 277-294. 
Van Tuin, L., Schaufeli, W. B., \& Van Rhenen, W. (2020). The satisfaction and frustration of basic psychological needs in engaging leadership. Journal of Leadership Studies, 14(2), 6-23.

Veldhoven, M. V., \& Meijman, T. (1994). Het meten van psychosociale arbeidsbelasting met een vragenlijst: de vragenlijst beleving en beoordeling van de arbeid (VBBA) [Measuring psychosocial workload with a questionnaire: The questionnaire on the experience and assessment of work (QEEW)]. Nederlands Instituut voor Arbeidsomstandigheden.

Zhao, X., Lynch, J. G., \& Chen, Q. (2010). Reconsidering Baron and Kenny: Myths and truths about mediation analysis. Journal of Consumer Research, 37, 197-206.

\section{Appendix I}

\section{Validity of autonomy supportive and controlling leadership style measures}

Since we measured autonomy supportive leadership using Baard et al.'s (2004) scale and controlling leadership with a new measure, we provide validity data for these instruments. From a theoretical point of view, our measures operationalize the same constructs as the Perceived Autonomy Support Scale for Employees (PASS-E) by Moreau and Mageau (2012), which is often used for assessing employees' perceived autonomy support and control from work supervisors (Slemp et al., 2018). Therefore, in terms of items, our measures share resemblance with the measures of Moreau and Mageau (2012). For example, to assess leaders' autonomy support, both the measures of Moreau and Mageau (2012) and that of Baard et al. (2004) include questions regarding choice (e.g., "My supervisor(s) give me many opportunities to make decisions in my work" and "I feel that my manager provides me choices and options," respectively) and perspective taking (e.g., "My supervisor(s) take the time to listen to my opinion and my point of view when I disagree with them" and "My manager tries to understand how I see things before suggesting a new way to do things," respectively).

In measuring controlling leadership too, both Moreau and Mageau's (2012) scale and our measure of controlling leadership capture the shift in employees' locus of control or self-determination (e.g., "My supervisor(s) do not take the time to ask me to do something, they order me to do it" and "My supervisor is demanding and strict," respectively) and the induction of negative feelings when employees do not act or think in line with the supervisor's orders (e.g., "My supervisor(s) try to make me feel bad when they are not satisfied with my work" and "My supervisor is less friendly to me when I don't see things the way he or she sees them," respectively).

Empirically, we assessed the validity of the measures used in our research vis a vis Moreau and Mageau's (2012) scale, and the Multidimensional Work Motivation Scale by Gagné et al., (2015) — a scale used for measuring different employee motivations that result from having an autonomy supportive or controlling leader. We collected responses from an additional sample of 200 employees via the online platform Prolific in May 2021. Participation was voluntary and anonymous and informed consent was obtained from all participants. The sample comprised currently employed (77.5\% full time and $22.5 \%$ part-time) participants whose first language was English. The results are displayed in Table 5 in Appendix 1.

Results supported the convergent validity of our measures as our scales of autonomy supportive and controlling leadership - as used in Study 1 and Study 2-correlated highly with Moreau and Mageau's (2012) items of autonomy support and control (see Table 5 in Appendix 1). Note that, despite the single item difference in our autonomy supportive and controlling leadership scales in Study 1 and Study 2, the correlation between both scales was found to

Table 5. Means, standard deviations, Cronbach's alphas, and correlations among the study variables of validity study.

\begin{tabular}{|c|c|c|c|c|c|c|c|c|c|c|}
\hline & $M$ & $S D$ & I & 2 & 3 & 4 & 5 & 6 & 7 & 8 \\
\hline I. AUTMOT & 4.71 & 1.49 & $(.91)$ & & & & & & & \\
\hline 2. CONMOT & 3.53 & 1.22 & $.4 I^{* *}$ & $(.87)$ & & & & & & \\
\hline 3. MMPAS & 4.90 & 1.22 & $.59 * *$ & $.23 * * *$ & $(.92)$ & & & & & \\
\hline 4. MMPCS & 1.91 & 1.06 & $-.21 * *$ & $.18 * * *$ & $-.5 I^{* *}$ & $(.92)$ & & & & \\
\hline 5. SIASL & 3.67 & 0.99 & $.55^{* *}$ & $.13^{*}$ & $.86 * *$ & $-.53 * *$ & $(.94)$ & & & \\
\hline 6. SICL & 1.84 & 0.86 & $-.18 * *$ & $.21 * *$ & $-.56 * *$ & $.76 * *$ & $-.57 * *$ & $(.84)$ & & \\
\hline 7. S2ASL & 3.71 & 0.99 & $.54 * *$ & $.14 *$ & $.85^{* *}$ & $-.53 * *$ & $.99 * *$ & $-.56^{* *}$ & $(.93)$ & \\
\hline 8. $\mathrm{S} 2 \mathrm{CL}$ & 1.86 & 0.83 & $-.22 * *$ & $.20 * *$ & $-.58^{* *}$ & $.74 * *$ & $-.58 * *$ & $.97 * *$ & $-.57 * *$ & $(.80)$ \\
\hline
\end{tabular}

SD: standard deviation; AUTMOT: Autonomous Motivation; CONMOT: Controlled Motivation; MMASL: Moreau and Mageau's (2012) measure of perceived autonomy support from supervisor; MMCL: Moreau and Mageau's (2012) measure of perceived supervisor control; SIASL: Study I's measure of autonomy supportive leadership; SICL: Study I's measure of controlling leadership; S2ASL: Study 2's measure of autonomy supportive leadership; S2CL: Study 2's measure of controlling leadership.

$N=200$. Cronbach's alphas are reported on the diagonal.

$* p<.05$.

$* * p<.01$.

$* * * p<.001$ 
be very high. Hence, both measures could be considered (almost) identical.

Furthermore, in line with the tenets of SDT and akin to the measures of Moreau and Mageau (2012), our measures of autonomy supportive leadership associated more strongly and positively with autonomous motivation than with controlled motivation. Notably, the positive association between autonomy supportive leadership and controlled motivation could be due to the general factor of motivation which, as outlined in SDT, is shared among all types of motivation, and hence, could also explain the positive correlation between autonomous and controlled motivation (Howard et al., 2018). Much like Moreau and Mageau's (2012) items of perceived supervisory control, our measures of controlling leadership also associated positively with controlled motivation, while relating negatively with autonomous motivation. In sum, these results provide support for the predictive validity of our measures. 